\title{
De lange en moeizame weg naar Customer Profitability Analysis (CPA)
}

\section{Michael Corbey en Regine Slagmulder}

SAMENVATTING Customer Profitability Analysis (CPA) is een methode om de winstgevendheid van klanten te analyseren. Als basisaanpak dient hierbij Activity Based Costing ( $\mathrm{ABC}$ ) waarna opbrengsten en kosten worden gealloceerd aan klanten. Dit maakt het mogelijk om diagrammen als de customer piramid en de whale curve op te stellen. CPA gaat echter verder: voordat assortimentsbeslissingen worden genomen, dient ook rekening te worden gehouden met de resterende constante kosten, effecten met betrekking tot crossselling, de levensfase van het product en de levensfase van klant. Bij vaststelling van deze effecten stuit men op aanzienlijke (meet)problemen. Dit maakt CPA tot een moeizame exercitie en men dient zich serieus af te vragen of de inspanning de moeite waard is. Het artikel besluit met de bespreking van enige contingentiefactoren die pleiten voor toepassing van CPA (wanneer wel?)

\section{Inleiding}

Veel ondernemingen hebben de laatste jaren hun productassortiment zien groeien. Vaak heeft dit ook geleid tot een groei van het klantenbestand. Op zich is hier natuurlijk niets mis mee, ware het niet dat lang niet alle nieuwe producten en klanten winstgevend blijken te zijn.

Vaak blijft het bij een intuïtief gevoel van de ondernemingsleiding dat er bleeders in het assortiment zitten dan wel dat er klanten zijn waar 'geld bij moet'. Customer Profitability Analysis (CPA) is een systematische

Prof. Dr. Ir. M. Corbey is hoogleraar Management Accounting \& Control aan Tias Business School, Universiteit van Tilburg. Hij is daar tevens Academic Director van de postdoctorale opleiding tot registercontroller.

Prof. Dr. Ir. R. Slagmulder is Associate Professor of Accounting \& Control aan INSEAD te Fontainebleau, Frankrijk. aanpak waarbij de klantwinstgevendheid zichtbaar wordt gemaakt. In paragraaf 2 wordt de CPA-aanpak besproken. Helaas kent een CPA-onderzoek aanzienlijke (meet)problemen. Deze worden besproken in paragraaf 3. Zoals de titel van dit artikel al suggereert, is een CPA-onderzoek in de praktijk beslist niet eenvoudig. Bezint eer ge begint, is het devies; in paragraaf 4 bespreken we daarom enige contingentiefactoren met betrekking tot CPA. Slotopmerkingen volgen in paragraaf 5 .

\section{Wat is Customer Profitability Analysis?}

Er is in de recente literatuur geen eenduidige, messcherpe, alom aanvaarde definitie van Customer Profitability Analysis (CPA) te vinden. In ieder geval is men het er over eens dat CPA betrekking heeft op de allocatie van opbrengsten en kosten naar klantsegmenten dan wel individuele klanten zodanig dat de winstgevendheid van deze segmenten of klanten kan worden bepaald. Het is dus niet het product dat centraal staat, maar de klant(segmenten). Men spreekt daarom in dit verband ook wel van Customer Accounting (Guilding en McManus, 2002).

Foster, Gupta en Sjöblom (1996, p. 10) noemen nog andere kenmerkende eigenschappen van CPA:

- het is gericht op de totale waardeketen, zie voor meer uitleg paragraaf 3.1;

- de analyse is niet gericht op één, maar juist op vele transacties;

- de analyse is niet gericht op één product, maar juist op vele verschillende producten;

- er wordt onderscheid gemaakt in klantspecifieke kosten; en

- er kan zowel op detailniveau als op geaggregeerd niveau worden geanalyseerd.

Guilding en McManus (2002) trachten enige orde te scheppen in de vele benaderingen van CPA. Zij stel- 
len een raamwerk voor waarin plaats is voor vijf onderwerpen die betrekking hebben op wat zij Customer Accounting (CA) noemen. Deze vijf onderwerpen zijn:

1 Customer Profitability Analysis;

2 Customer Segment Profitablility Analysis;

3 Lifetime Customer Profitability Analysis;

4 Valuation of Customers or Customer Groups as Assets;

5 Customer Accounting (dit omvat de bovenstaande vier ('the holistic approach')'.

De basis van alle vormen van CPA wordt gevormd door de allocatie van kosten. Hierover meer in de volgende paragraaf.

\subsection{Kostenallocatie}

Kostenallocatie betreft het toerekenen van kosten aan producten, of, in het geval van CPA, aan klanten. De moeilijkheid zit hem hier vooral in de toerekening van de indirecte kosten, dit zijn kosten waarvan het niet duidelijk is (geen direct causaal verband) voor welk product ze worden gemaakt (of voor welke klant). Cardinaels, Roodhooft en Warlop (2004) waarschuwen in dit verband voor de hantering van volumesleutels om deze kosten toe te rekenen. Het volgende citaat is illustratief:

'Traditional cost reports often assume that marketing costs increase with volume, whereby each dollar of revenue contributes equally to net income (Selnes, 1992). Hence, variations in marketing support remain hidden and it is more likely that resources are misallocated to the customers with low profit potential. On the other hand, customer profitability $\left(\mathrm{CuPA^{2 } )}\right.$ reports typically use non-volume based cost drivers (e.g., the number of deliveries, orders, etc.) of activity based costing to accurately reflect important variations in marketing support across customers (Foster et al., 1996; Kaplan and Atkinson, 1998).' (Cardinaels, Roodhooft en Warlop, 2004, p. 239)

Deze auteurs pleiten er dus voor om Activity Based Costing (ABC) te gebruiken als allocatiemethode. ABC is inderdaad alom aanvaard als de meest nauwkeurige vorm van kostenallocatie. Voor een beschrijving van $\mathrm{ABC}$ verwijzen we naar de handboeken, zie bijvoorbeeld Cooper en Kaplan (1999). We moeten hierbij wel opmerken dat de implementatie van $\mathrm{ABC}$ bepaald geen sinecure is, men spreekt in dit verband wel van de ABC-paradox, we komen hierop terug in paragraaf 3.

Als het gaat om de allocatie van opbrengsten, dan zien we minder problemen. In de regel zal het wel duide- lijk zijn (direct causaal verband) welke opbrengsten bij welke klanten horen.

Laten we nu eens aannemen dat de resultaten van de opbrengsten en kostenallocatie bekend zijn. In dat geval namelijk, is het mogelijk om een aantal typische CPAdiagrammen en grafieken te maken. Een bekend diagram is bijvoorbeeld de Customer Piramid (Zeithaml, Rust en Lemon, 2001). In deze driehoekige figuur worden de klanten ingedeeld in vier groepen, van topklanten tot kleine klanten. Een voorbeeld van een dergelijk diagram ziet $\mathrm{u}$ in figuur 1.

Figuur 1. Voorbeeld van een Customer Piramid (ontleend aan Van Raaij, Vernooij en Van Triest, 2003, p. 578).

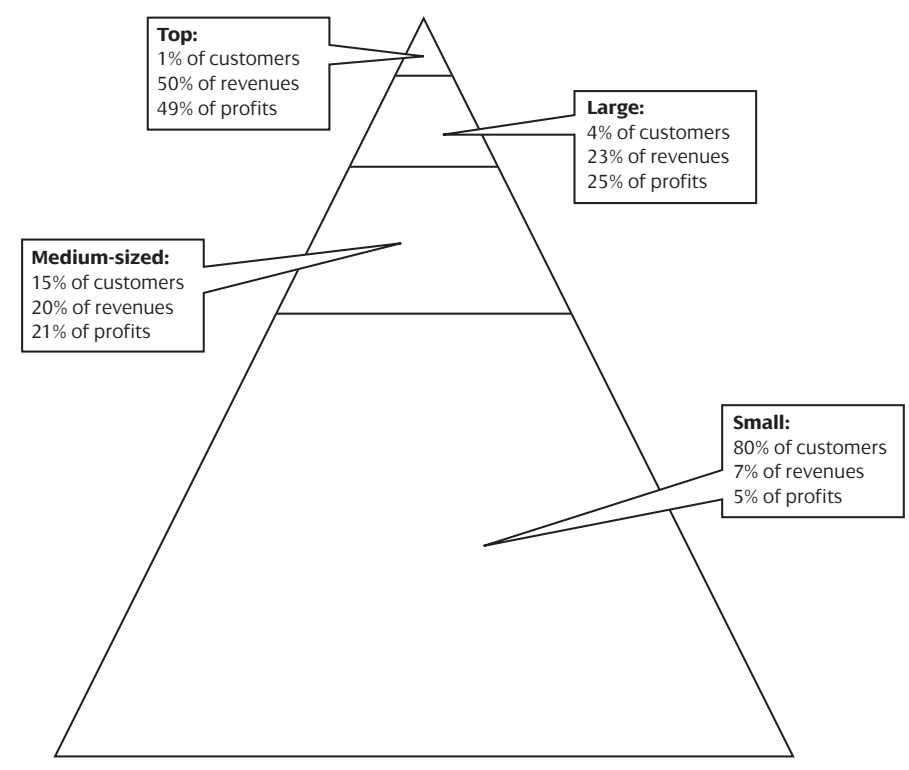

Een andere, bekende grafiek is de zogenaamde whalecurve (Cooper en Kaplan, 1999) ${ }^{3}$. In deze curve ordent men op de $\mathrm{X}$-as van links de meest winstgevende klanten naar rechts de minst winstgevende (dan wel verlieslatende) klanten. De Y-as bestaat uit de cumulatieve winst. Het resultaat is vaak een figuur die, met enige fantasie, lijkt op een walvis die uit het water opduikt. Vandaar de naam. Cooper en Kaplan (1999) spreken in dit verband ook wel van de 225-20 regel: in sommige (extreme) gevallen zorgen de $20 \%$ beste klanten voor $225 \%$ van de winst. De overige $80 \%$ van de klanten reduceren de $225 \%$ winst tot $100 \%$, er is dus een groot deel verliesgevende klanten. Een voorbeeld van een whalecurve is figuur 2. 
Figuur 2. Voorbeeld van een whalecurve (ontleend aan Cooper en Kaplan, 1999, p. 284).

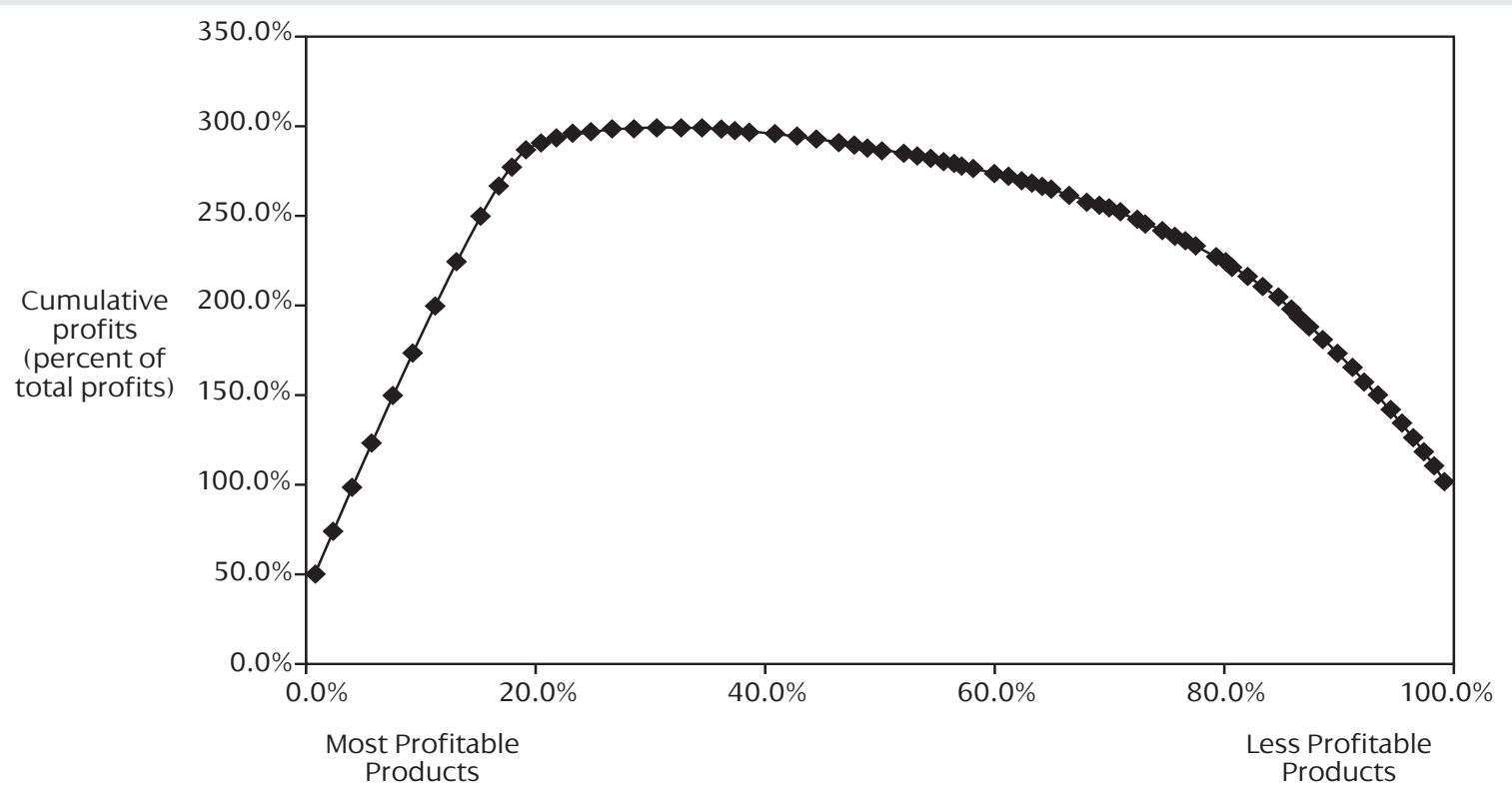

Een analyse die men ook vaak ziet, betreft een 2 bij 2 matrix waarin men de klanten indeelt in klanten met een hoge marge en klanten met een lage marge en dit relateert aan de cost to serve, die ook hoog dan wel laag kan zijn. Figuur 3 betreft een voorbeeld van zo'n matrix.

Figuur 3. Marges en cost to serve (ontleend aan Cooper en Kaplan, 1999, p. 344)

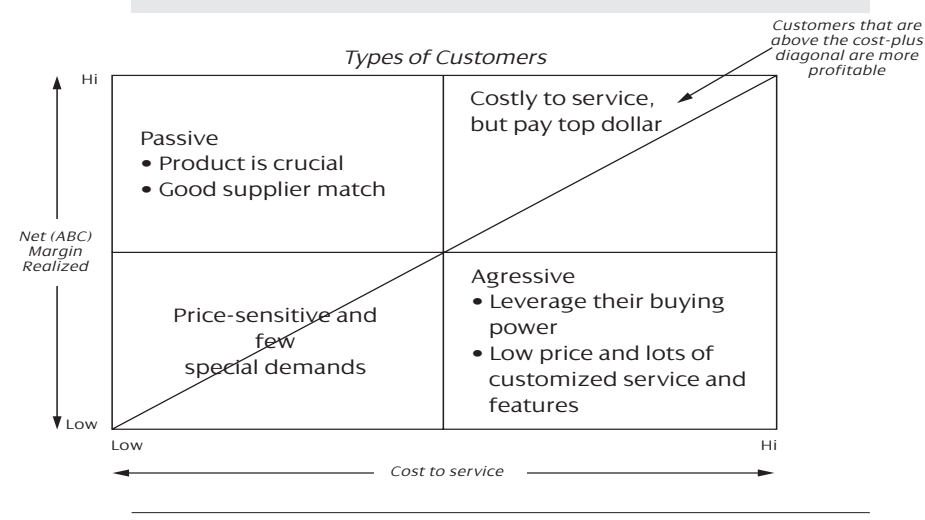

Het zal duidelijk zijn dat de analyse inzicht verschaft in de winstgevendheid (en verlieslatendheid) van de klantportfolio van een onderneming. Toch moet worden gewaarschuwd voor het trekken van overhaaste conclusies op grond van de bovenstaande analyse. Zo'n overhaaste conclusie zou kunnen zijn om resoluut (en zonder verder onderzoek) afscheid te nemen van de verliesgevende klanten.

\subsection{De essentie van CPA: geen overhaaste conclusies}

De conclusie tot 'koude sanering' van de klantportfolio is overhaast om een aantal redenen. Ten eerste het probleem van de gealloceerde constante kosten. De verliesgevende klanten hebben uiteraard een deel van de constante kosten toegerekend gekregen. $\mathrm{Na}$ afscheid van de klanten resteren de constante kosten (dat is immers de reden waarom ze constant zijn). Er zit niets anders op dan deze constante kosten te heralloceren naar de overgebleven klanten. Maar, dat zal betekenen dat er een nieuwe groep verliesgevende klanten gaat ontstaan (omdat ze meer constante kosten moeten dragen). Indien men ook van deze groep afscheid neemt, dient opnieuw herallocatie plaats te vinden, enzovoort. Aan het einde van deze dodelijke spiraal blijft men over met nul klanten en nog altijd evenveel constante kosten als in het begin.

Een tweede reden om niet overhaast tot sanering over te gaan, zijn fenomenen als cross-selling en cross-buying, we spreken verder kortweg over cross-selling. Dit houdt bijvoorbeeld in dat een klant op zich verliesla- 
tend kan zijn, maar dat de aanwezigheid zorgt voor de verwerving van andere, wel winstgevende klanten. Sanering van de verliesgevende klant leidt dan ook tot verlies van andere klanten. Cross-selling speelt overigens ook op productniveau. Bekende voorbeelden in de supermarkt zijn bier en frisdrank. Dit zijn notoire bleeders, maar geen supermarkt die ze uit het assortiment verwijdert. Het risico is immers te groot dat de bierdrinker dan ook maar gelijk al zijn boodschappen elders inkoopt. Ook bij banken zien we vaak dat het standaardproduct (de gewone bankrekening) verliesgevend is, maar wel zorg draagt voor aanzienlijke cross-selling van bijvoorbeeld verzekeringsproducten.

Een derde reden tot voorzichtigheid betreft de fase in de productlevenscyclus van de producten die de verliesgevende klant afneemt. De ABC-analyse betreft een momentopname, een product dat zich toevallig in de introductiefase bevindt, zal naar alle waarschijnlijkheid veel indirecte kosten veroorzaken en weinig verkoopvolume. Het zal dus een bleeder zijn op dit moment. Maar, in de groei- en rijpheidsfase zal de hoeveelheid indirecte activiteiten afnemen (bijvoorbeeld wegens de leercurve) terwijl het verkoopvolume toeneemt. Het product (en daarmee dus ook de klant) heeft dus grote kans later wel winstgevend te worden.

Een vierde reden die tot voorzichtigheid noopt, is de levensfase van de klant. Een bekend voorbeeld is de studentenbankrekening. Een ABC-analyse op het niveau van de klant (de student) zal vaak laten zien dat de klant verliesgevend is. Toch is het niet verstandig om afscheid te nemen want zodra de student afstudeert, gaat hij naar alle waarschijnlijkheid werken, wellicht een huis kopen, een gezin stichten, en dergelijke meer. Kortom, de huidige verliesgevende klant kan wel degelijk winstgevend worden in een latere fase van zijn leven. $\mathrm{Nu}$ afscheid nemen is dan onverstandig.

Samenvattend kunnen we opmerken dat CPA begint met een $\mathrm{ABC}$-analyse. De uitkomsten van die analyse zijn nodig, maar niet voldoende om tot verantwoorde beslissingen te komen. Daarvoor moet ook rekening worden gehouden met de resterende constante kosten, cross-selling, de levensfase van het product en de levensfase van de klant. Deze fenomenen komen in de praktijk gelijktijdig voor en dienen voor het gehele productassortiment en klantenbestand onderzocht te worden. Dat betekent nogal wat. In de volgende paragraaf gaan we in op de problemen met betrekking tot CPA.

\section{Problemen met betrekking tot Customer Profitability Analysis}

Bij de bespreking van de problemen zullen we allereerst stilstaan bij ABC (en met name bij de al eerder genoemde ABC-paradox). Daarna komen de overige problemen met betrekking tot onder meer (het meten van) klantwaarde aan de orde.

\subsection{Allocatieproblemen en de ABC-paradox}

Eerder werd opgemerkt dat CPA betrekking moet hebben op de gehele waardeketen. Het is niet vanzelfsprekend dat Activity Based Costing (ABC) voldoet aan dit criterium. Vaak is een ABC-prijs 'af fabriek', hetgeen betekent dat geen rekening wordt gehouden met downstream costs die vaak zeer aanzienlijk kunnen zijn. Denk hierbij aan distributiekosten tot en met garantiekosten. Juist in dit traject zien we vaak dat de verschillen tussen high cost to serve en low cost to serve klanten ontstaan. Dit traject mag dus zeker niet worden weggelaten in de ABC-analyse.

Een soortgelijke opmerking kunnen we maken voor pre-sale costs. Ook deze zitten vaak niet verwerkt in de standaard ABC-kostprijs. Maar, zoals we weten kunnen deze pre-sale costs in het geval van vergelijkende aanbestedingen (bijvoorbeeld in de bouwwereld!) zeer aanzienlijk zijn. Ook deze moeten dus worden meegenomen in de ABC-analyse.

Een fundamenteler probleem betreft een verschijnsel dat in de literatuur bekend staat als de ABC-paradox, zie bijvoorbeeld Gosselin (1997) en Schoute (2003). Zoals hierboven reeds aangehaald, zijn CPA-systemen doorgaans gebaseerd op ABC-informatie aangezien een goed ontworpen $\mathrm{ABC}$-systeem de cost to serve op een inzichtelijke manier kwantificeert. Opmerkelijk is echter dat veel bedrijven blijken af te zien van een ABC-systeem ondanks de algemeen bejubelde voordelen van deze aanpak, zoals een meer accurate kostenallocatie en bijgevolg een betere beheersing van de overheadkosten. Hoewel surveyresultaten met betrekking tot de adoptiegraad van ABC sterk variëren al naargelang de bron, valt het in het algemeen op dat $\mathrm{ABC}$ nog steeds geen gemeengoed is in de overgrote meerderheid van de bedrijven. Als belangrijkste reden voor het relatief lage adoptiepercentage verwijst men meestal naar de enorme investeringen in tijd en middelen die nodig zijn voor het implementeren en up-todate houden van een goed werkend $\mathrm{ABC}$-systeem. Zelfs Robert Kaplan, een van de pioniers van ABC, erkent dit probleem en heeft daarom recentelijk een 
eenvoudiger en flexibeler vorm van $\mathrm{ABC}$ in de markt gelanceerd, de time-driven $\mathrm{ABC}$ (Kaplan en Anderson, 2004). Of deze nieuwe aanpak inderdaad de verwachte doorbraak van $A B C$ zal bewerkstelligen dan wel de spreekwoordelijke pleister op de wonde is, blijft voorlopig een open vraag. Het is echter duidelijk dat CPA nooit echt op grote schaal ingeburgerd zal geraken als de ABC-methode waarop het gestoeld is, slechts door weinig bedrijven actief wordt toegepast.

\subsection{Overige problemen}

Behalve de investering in een $\mathrm{ABC}$-systeem komen daar bij CPA vaak nog investeringen van zes cijfers bovenop in datawarehouses en informatiesystemen voor het verzamelen en analyseren van alle detailgegevens inzake opbrengsten, kosten, transactievolumes, klantengedrag, enzovoort, die dienen als input voor de winstgevendheidsberekeningen, alsook in de opleiding van medewerkers en het creëren van teams van specialisten voor het analyseren van de resultaten. Nemen we het voorbeeld van Royal Bank of Canada, die maandelijks de winstgevendheid van elk van zijn 10 miljoen retailklanten berekent, wat een massale dataverwerking impliceert. Een cliënt kan bijvoorbeeld een bepaalde winst voor de bank opleveren voornamelijk als gevolg van de interesten die worden verdiend op een hoog gemiddeld saldo op de rekening, terwijl een andere cliënt met een veel lager gemiddeld saldo en dus lagere interesten - misschien hetzelfde winstniveau oplevert voor de bank maar dan dankzij de extra premies als gevolg van frequente geldopnames, geweigerde checks en overschrijding van de kredietlimiet. Om nuttige conclusies te kunnen trekken uit klantenwinstgevendheidsgegevens is het dus noodzakelijk dat bedrijven voldoende detailinformatie hebben over de achterliggende drivers van die winst om aldus gerichte marketingstrategische beslissingen te kunnen nemen. Maar zoals gezegd, hangt aan deze gedetailleerde informatie een fiks prijskaartje.

Een bijkomend probleem is dat de meeste CPA-systemen, ondanks de zware investeringen in dataverzameling en analyse, in de praktijk hoofdzakelijk informatie afleveren over de huidige of historische winstgevenheidstoestand van klanten. Zoals gezegd is het in veel gevallen veel interessanter om een beeld te hebben van de toekomstige winstgevendheid, zelfs over de hele levencyclus van de klant. Alhoewel diverse methodes en systemen voor het bepalen van de toekomstige verwachte winstgevendheid ontwikkeld zijn, worden ze slechts weinig toegepast in de praktijk. De complexiteit van de analyses en het eerder subjec- tieve karakter van de inschattingen van toekomstig klantengedrag vormen blijkbaar een moeilijk te overschrijden drempel voor de meeste bedrijven. Voor een overzicht van Customer Lifetime Value modellen en de bijbehorende problemen verwijzen we verder naar Verhoef (2004).

Naast deze informatiegerelateerde problemen kampen veel bedrijven bij CPA echter ook met een aantal organisatorische en gebruiksgerelateerde problemen. Zo is er de typische weerstand tegen verandering die een belangrijke barrière kan vormen bij de invoering van een CPA-systeem en die gewoonlijk gepaard gaat met initieel wantrouwen in de nieuwe informatie. De steun van de bedrijfstop dient zich daarom niet enkel te vertalen in het financieren van het implementatietraject, maar ook in het systematisch onderstrepen van het belang van CPA in beslissingen over het aantrekken van nieuwe klanten of het versterken van de relatie met bestaande winstgevende klanten.

Zelfs als de CPA-informatie beschikbaar is op bedrijfsniveau, blijft het nog de vraag of de verkoopafdelingen voldoende geïnformeerd zijn over de winstgevendheid van hun klantenportefeuille. In bepaalde bedrijven circuleert men deze informatie liever enkel binnen beperkte kring (wegens het vertrouwelijke karakter van de informatie), maar dat betekent ook dat de frontline-medewerkers die rechtstreeks met klanten in contact komen, vaak beslissingen nemen die haaks staan op de aanbevelingen die voortvloeien uit een strategische CPA-analyse.

Ten slotte lijden nogal wat bedrijven die zich wagen aan CPA aan het 'analysis paralysis'-syndroom: verlamd door de veelheid aan informatie weet men vaak niet welke problemen of kansen als eerste aan te pakken. Bovendien blijken nogal wat CPA-projecten te falen omdat vaak de moed ontbreekt om - soms pijnlijke - beslissingen te nemen indien blijkt dat bepaalde klanten(segmenten) of projecten structureel waarde vernietigen. Zolang er echter geen concrete acties worden genomen om de winstgevendheid van de klantenportefeuille en aldus de financiële resultaten van het bedrijf op te krikken, blijft CPA-informatie dode letter.

\section{Wanneer wel CPA? Enige contingentiefactoren}

Zoals hierboven besproken, is het succes van het onderliggende $\mathrm{ABC}$-systeem een conditio sine qua non voor een succesvolle implementatie van CPA. Empirisch onderzoek heeft gepoogd een verklaring te vinden voor de eerder besproken ABC-paradox (Gosselin, 
1997; Schoute, 2003). Factoren zoals de strategie van de onderneming inzake verticale differentiatie, de graad van formalisatie en decentralisatie bleken duidelijk gecorreleerd te zijn met de adoptiegraad van ABC. Voorzichtig extrapolerend lijken deze resultaten erop te wijzen dat bedrijven met een hoge graad van formalisatie meer geneigd zullen zijn om CPA te implementeren en ook een grotere kans hebben op tevredenheid met hun CPA-systeem.

Op basis van de bescheiden hoeveelheid onderzoek die gepubliceerd werd rond dit onderwerp en observaties uit de bedrijfswereld onderscheiden we drie factoren ten gunste van CPA: strategie, organisatiestructuur en prestatiemeetsysteem. Wat de strategie van het bedrijf betreft, ontdekten Guilding en McManus (2002) in hun empirische studie een duidelijk positief verband tussen de graad van marktoriëntatie en het gebruik van complexere CPA-technieken. Deze bevinding wordt ondersteund in de recente Customer Relationship Management (CRM) literatuur, die het duidelijk formuleren van een klantgerichte strategie aanhaalt als een van de kritieke succesfactoren voor een succesvol CRM-programma, waarvan CPA vaak deel uitmaakt (Rigby et al, 2002). We durven zelfs verder te gaan en de stelling te poneren dat CPA enkel zijn nut kan bewijzen in bedrijven met een uitgesproken klantgerichte strategie en veel minder in bedrijven die een lage-kostenstrategie nastreven.

De tweede contingentiefactor betreft de organisatiestructuur. Een structuur op basis van klantensegmenten leent zich veel beter tot CPA dan de klassieke productgebaseerde structuur. In een traditionele organisatie loopt de crossfunctionele samenwerking tussen bijvoorbeeld marketing en financiën vaak stroef. De inzichten op basis van CPA worden namelijk doorgaans gegenereerd in de financiële afdeling, maar deze informatie stroomt niet altijd even makkelijk door naar de marketingafdeling, en vaak is het dan nog een black box. Ofwel wordt het CPA-project overwegend gerund door marketingmensen, maar dan stellen de accountants zich sceptisch op omdat deze winstgevendheidcijfers niet altijd perfect te verzoenen zijn met het grootboek. In een klantgeoriënteerde organisatie daarentegen loopt de CPA-informatie op natuurlijke wijze parallel met de beslissingskanalen en ondersteunt de organisatiecultuur ook het hele CPA-proces.

Ten slotte is er het belang van het goed afstemmen van de prestatiebeoordeling en beloning van commerciële medewerkers op basis van CPA-informatie in plaats van verkoopvolume. Bedrijven die voor hun prestatiemeting gebruikmaken van een Balanced Scorecard doen er bijvoorbeeld goed aan CPA-maatstaven expliciet op te nemen als onderdeel van de prestatie-indicatoren in het klantenkwadrant. Zoals bij de meeste prestatieverbeteringsinitiatieven is het belangrijk dat CPA deel uitmaakt van het dagelijks jargon en dat goede resultaten zichtbaar worden gemaakt als benchmarks voor de rest van de organisatie. Barclays Bank, een van de pioneers op het vlak van CPA in Europa, heeft dit tijdig ingezien. De bank streeft een geïntegreerde aanpak na waarbij CPA onderdeel is van een alles overkoepelende strategie die gericht is op waardecreatie en gekenmerkt wordt door een expliciete klantenfocus. Sales targets en incentives zijn daarbij rechtstreeks gekoppeld aan CPA-informatie.

\section{Slotopmerkingen}

Customer Profitability Analysis (CPA) is een methode om de winstgevendheid van klanten te analyseren. Als basisaanpak dient hierbij Activity Based Costing (ABC) waarna opbrengsten en kosten worden gealloceerd aan klanten. Dit maakt het mogelijk om diagrammen als de customer piramid en de whale curve op te stellen. CPA gaat echter verder: voordat beslissingen worden genomen, dient ook rekening te worden gehouden met de resterende constante kosten, effecten met betrekking tot cross-selling, de levensfase van het product en de levensfase van de klant. Bij vaststelling van deze effecten stuit men op (aanzienlijke meet)problemen. Het aantal succesvolle toepassingen van CPA blijkt dan ook beperkt te zijn. De contingentiefactoren duiden erop dat CPA minder geschikt is voor bedrijven met een lage-kostenstrategie, en/of met een productgerichte (functionele) structuur en/of met sales incentives die niet gekoppeld zijn aan CPA. 


\section{Literatuur}

Cardinaels, E., F. Roodhooft en L. Warlop, (2004), Customer Profitability Analysis Reports for Resource Alloaction: The Role of Complex Marketing Environments, in: Abacus, vol. 40, no. 2, pp. 238-258.

Cooper, R. en R.S. Kaplan, (1999), The Design of Cost Management Systems, Prentice Hall, Upper Saddle River.

Foster, G., M. Gupta en L. Sjöblom, (1996), Customer Profitability Analysis, Challenges and New Directions, in: Journal of Cost Management, vol.10, Spring, pp. 5-17.

Gosselin, M., (1997), The Effect of Strategy and Organizational Structure on the Adoption and Implementation of Activity-based Costing, in: Accounting Organizations and Society, vol. 22, p. 105-122.

Guilding, C. en L. McManus, (2002), The Incidence, Perceived Merit and Antecedents of Customer Accounting, an Explenatory Note, in: Accounting Organizations and Society, vol. 27, no. 1, pp. 45-59.

Kaplan, R.S. en A.A. Atkinson, (1998), Advanced Management Accounting, 3rd ed., Prentice Hall, Upper Saddle River.

Kaplan, R.S. en S.R. Anderson, (2004), Time-Driven Activity-Based Costing, in: Harvard Business Review, November 2004, pp. 131-139.

Raaij, E.M. van, M. J.A. Vernooij en S. van Triest, (2003), The Implementation of Customer Profitability Analysis, a Case Study, in: Industrial Marketing Management, vol. 32, pp. 573-583.

Rigby, D., F. Reichheld en P. Schefter, (2002), Avoid the Four Perils of CRM, inL: Harvard Business Review, vol. 80, no. 2, February, pp. 101-109.

Schoute, M., (2003), De ABC-paradox nader beschouwd, in: Maandblad voor Accountancy en Bedrijfseconomie, vol. 77, no. 7/8, juli-augustus, pp. 332-339.

Selnes, F., (1992), Analyzing Marketing Profitability: Sales are a Dangerous Cost Driver, in: European Journal of Marketing, vol. 26, no. 2, pp. 15-26.

Verhoef, P.C., (2004), Customer Lifetime Value, een overzicht van de literatuur, in: Tijdschrift voor Economie en Management, vol. 49, no. 1, pp. 79-105.

Zeithaml, V.A., R.T. Rust en K.N. Lemon, (2001), The Customer Pyramid, Creating and Serving Profitable Customers, in: California Management Review, vol. 43, no. 4, pp. 118-142.

\section{Noten}

1 Wij volgen de suggestie van deze auteurs om het geheel Customer Accounting (CA) te noemen, overigens niet. Ondanks sommige verschillen in lading, lijkt de term CPA toch de vlag te zijn die het meest is geaccepteerd

2 Cardinaels, Roodhooft en Warlop gebruiken de samentrekking CuPA in plaats van CPA.

3 Men spreekt overigens ook wel van Stobachoff curves, zie Van Raaij, Vernooij en Van Triest (2004). 